\title{
Long-Haul Truck Sleeper Heating Load Reduction Package for Rest Period Idling
}

\author{
Jason Aaron Lustbader, Bidzina Kekelia, Jeff Tomerlin, and Cory J. Kreutzer \\ National Renewable Energy Laboratory \\ Skip Yeakel and Steven Adelman \\ Volvo Group North America \\ Zhiming Luo and John Zehme \\ Aearo Technologies LLC
}

\begin{abstract}
Annual fuel use for sleeper cab truck rest period idling is estimated at 667 million gallons in the United States, or $6.8 \%$ of long-haul truck fuel use. Truck idling during a rest period represents zero freight efficiency and is largely done to supply accessory power for climate conditioning of the cab. The National Renewable Energy Laboratory's CoolCab project aims to reduce heating, ventilating, and air conditioning (HVAC) loads and resulting fuel use from rest period idling by working closely with industry to design efficient long-haul truck thermal management systems while maintaining occupant comfort. Enhancing the thermal performance of cab/sleepers will enable smaller, lighter, and more cost-effective idle reduction solutions. In addition, if the fuel savings provide a one- to three-year payback period, fleet owners will be economically motivated to incorporate them. For candidate idle reduction technologies to be implemented by original equipment manufacturers and fleets, their effectiveness must be quantified. To address this need, several promising candidate technologies were evaluated through experimentation and modeling to determine their effectiveness in reducing rest period HVAC loads. Load reduction strategies were grouped into the focus areas of solar envelope, occupant environment, conductive pathways, and efficient equipment. Technologies in each of these focus areas were investigated in collaboration with industry partners. The most promising of these technologies were then combined with the goal of exceeding a $30 \%$ reduction in HVAC loads. These technologies included "ultra-white" paint, advanced insulation, and advanced curtain design. Previous testing showed more than a $35.7 \%$ reduction in air conditioning loads. This paper describes the overall heat transfer coefficient testing of this advanced load reduction technology package that showed more than a $43 \%$ reduction in heating load. Adding an additional layer of advanced insulation with a reflective barrier to the thermal load reduction package resulted in a $53.3 \%$ reduction in the overall heat transfer coefficient.
\end{abstract}

CITATION: Lustbader, J., Kekelia, B., Tomerlin, J., Kreutzer, C. et al., "Long-Haul Truck Sleeper Heating Load Reduction Package for Rest Period Idling," SAE Int. J. Passeng. Cars - Mech. Syst. 9(2):2016, doi:10.4271/2016-01-0258.

\section{INTRODUCTION}

In the United States, long-haul trucks (trucks that travel more than 500 miles per day) use approximately 667 million gallons of fuel annually for rest period idling [1]. Sleeper cab climate control is one of the primary reasons for idling the main engine during these driver rest periods. This rest period idling is approximately $6.8 \%$ of the total long-haul truck fuel use and represents a zero freight efficiency operating condition for the truck. Fuel is one of the largest trucking costs per mile, averaging $35 \%$ of the total from 2008 to 2013 [2]; therefore, the increasing cost and cost volatility of fuel provide a significant financial incentive to reduce fuel use. Recent federal, state, and city anti-idling regulations [ $\underline{3}]$ are providing further incentives to reduce truck idling. One example is the idle reduction technology credit in the Heavy-Duty Greenhouse Gas Emissions Standards, effective starting in 2014 [].
By reducing thermal loads and enabling more effective idle-off climate control systems, there is an opportunity to reduce fuel use and associated emissions. Enhancing the thermal performance of long-haul truck sleepers will enable smaller, lighter, and more cost-effective idle reduction solutions. In addition, if fuel savings from new technologies provide a one- to three-year payback period [ [5], fleet owners will be economically motivated to incorporate the new technologies.

Therefore, financial incentive provides a pathway to rapid adoption of effective thermal load and idle reduction solutions.

The U.S. Department of Energy's National Renewable Energy Laboratory's (NREL's) CoolCab project is researching efficient thermal management systems to maintain cab occupant comfort without the need for engine idling. The CoolCab project uses a system-level approach that addresses three aspects: reducing the thermal loads, efficient delivery of climate control for occupant 
thermal comfort, and maximizing equipment efficiency. By reducing thermal loads, the occupant's climate control needs are reduced, and reduced-capacity equipment can then provide the conditioning. To advance the goals of the CoolCab project and the broader goals of increased national energy security and sustainability, the CoolCab team works closely with industry partners to develop and apply commercially viable solutions to reduce national fuel use and industry costs.

To achieve an effective solution, NREL first conducted baseline testing of vehicles to quantify their thermal behavior. This information was then used to build and validate a CoolCalc model. CoolCalc is NREL's rapid HVAC load estimation tool []]. CoolCalc thermal models were then used in conjunction with experimental screening tests to identify promising thermal load reduction technologies. The most promising technologies were combined into a Complete-Cab Thermal Load Reduction Package. Previous tests showed that this reduced air conditioning $(\mathrm{A} / \mathrm{C})$ electrical loads by more than $35.7 \%$, exceeding the $30 \%$ goal []]. This paper describes testing of the impact of this Complete-Cab Thermal Load Reduction Package on heat loads using an overall heat transfer coefficient (UA) test procedure. This testing showed a $43 \%$ reduction in heating loads. The Complete-Cab Thermal Load Reduction Package was then updated with improved insulation (an additional thin layer of advanced insulation with a reflective barrier was added to the previously tested thermal insulation package), resulting in a UA heating load reduction of $53.3 \%$.

\section{APPROACH}

\section{Complete-Cab Thermal Load Reduction Package}

NREL has identified four key climate control load technology focus areas: conductive pathways, the solar envelope, occupant environment, and efficient equipment. The first three of these technologies impact the cab's heat transfer and resulting thermal loads and are the focus of this report. The efficient equipment focus area translates the thermal loads into mechanical or electrical loads. The four technical focus areas are described below.

1. The conductive pathways focus area addresses heat transfer through walls and other surfaces of the cab/sleeper. Technologies in this area include insulation, advanced materials, and glass.

2. The solar envelope describes the interaction of surfaces with radiant energy from the sun and the surrounding environment. It is predominantly driven by radiant heat transfer and is most relevant during daytime operation; however, nighttime radiation to the sky is also included. This focus area includes the study of opaque and transparent surface properties of paints and glass, respectively. It also includes devices to modify these properties, such as window shades.

3. The occupant environment includes the volume of conditioned air, occupant heat exchange with the surroundings, and human factors such as thermal sensation/comfort. Designing the thermal environment to make every occupant comfortable rather than to meet the traditional temperature-based metric has a significant impact on design. Technologies in this area include sleeper curtains and control of the microenvironment.
4. The use of efficient equipment impacts conversion of thermal loads to mechanical, electrical, or chemical loads. A range of technology options and design considerations falls into this category. These options include battery electric A/C, fuel-fired heaters, and auxiliary power units. For the purposes of this study, battery electric idle-off systems were used; however, the idle-off thermal load reduction technologies applied to the cab/ sleeper are largely independent of the equipment used.

Prior work used testing and modeling to down-select technologies from each of these focus areas to develop a Complete-Cab Thermal Load Reduction Package. The baseline experimental configuration for the test cab contained sections of insulation as part of the vehicle's stock insulation configuration. The stock insulation was affixed to portions of select upholstery panels that composed the sleeper compartment (Figure 1A). For the advanced insulation package, prefabricated insulation panels were installed throughout the sleeper compartment to occupy the void space between the upholstery panels and exterior frame wherever possible (igure 1B $)$. The advanced insulation package consisted of Thinsulate automotive acoustic insulation provided by Aearo Technologies. The areas of the sleeper cab insulation included the rear sleeper wall, sleeper ceiling, sleeper side walls, and portions of the cab ceiling. The installed insulation package contained a combination of one- and twoinchthick blanket insulation with a nominal thermal conductivity of between 0.03 and $0.05 \mathrm{~W} / \mathrm{m}-\mathrm{K}$. Prior testing of this load reduction package showed it to be effective for electrical load reduction for an electric-powered $\mathrm{A} / \mathrm{C}$ unit. To improve on this load reduction package, an additional 0.25 -inch layer of Thinsulate insulation with a reflective radiation barrier was added between the interior trim and cab structure to reduce thermal shorts between the wall structure and the interior (Figure 1C).

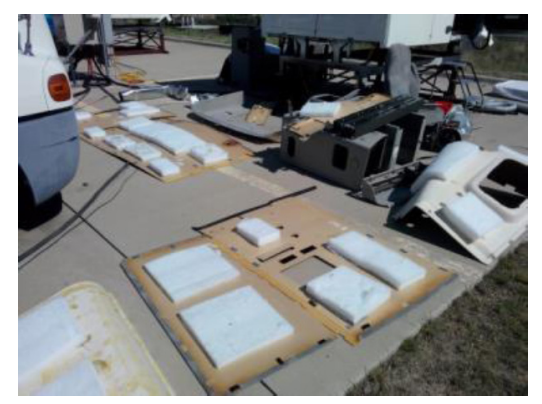

A.

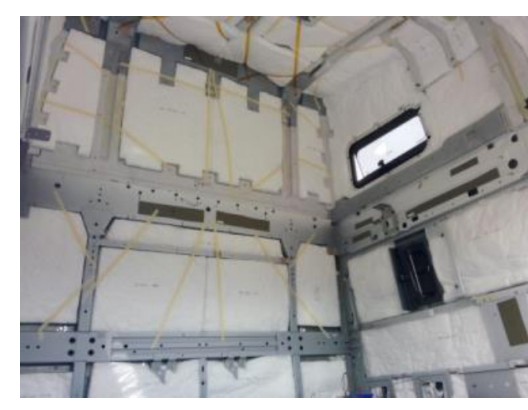

B.

Figure 1. A (top), stock insulation; B (center), advanced insulation; C (bottom), additional layer with reflective barrier 


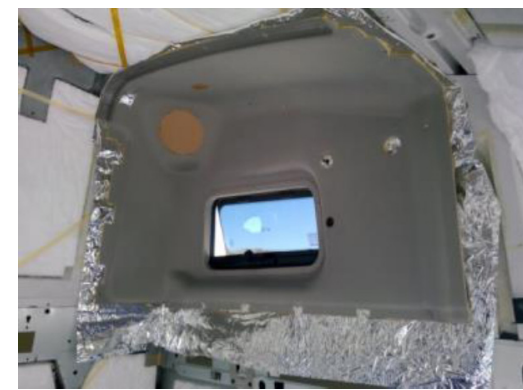

C.

Figure 1 (cont). A (top), stock insulation; B (center), advanced insulation; C (bottom), additional layer with reflective barrier

\section{Experimental Test Setup}

An overall heat transfer coefficient (UA) test program was conducted at NREL's Vehicle Testing and Integration Facility, shown in Figure $\underline{2 \mathrm{~A}}$, during the months of May through August. The facility is located in Golden, Colorado, at an elevation of 5,997 feet at latitude $39.7 \mathrm{~N}$ and longitude $105.1 \mathrm{~W}$. The experimental setup included two current model Volvo cab test "bucks." Both bucks were the cab section from a representative truck in current production provided by Volvo Trucks North America. One buck was utilized as the control buck, and the other was modified as the test buck.

For the experimental setup, the test and control bucks were oriented facing solar south and separated by a distance of 25 feet to maximize solar loading and minimize shadowing effects. To keep the firewalls from receiving direct solar loads, a firewall shade cloth was implemented on both the control and test bucks. In each vehicle, the sleeper curtain and four shades were available for use, depending on the test being conducted. The shades available were the front privacy, cab skylight, and two bunk window curtains.

The UA test procedure used to measure the heating performance of the Complete-Cab Thermal Load Reduction Package was conducted at night to eliminate solar loading effects. The sleeper air temperature of both bucks was controlled to $32^{\circ} \mathrm{C}$ using a forced air heater (Figure $\underline{2 \mathrm{~B}}$ ). This temperature was selected to provide a sufficient temperature difference of at least $10^{\circ} \mathrm{C}$ from the environment over the extended test season. Unless noted otherwise, the sleeper curtain and all four shades were used on the vehicles. All curtains and shades were employed to match the expected standard configuration during a rest period operation.
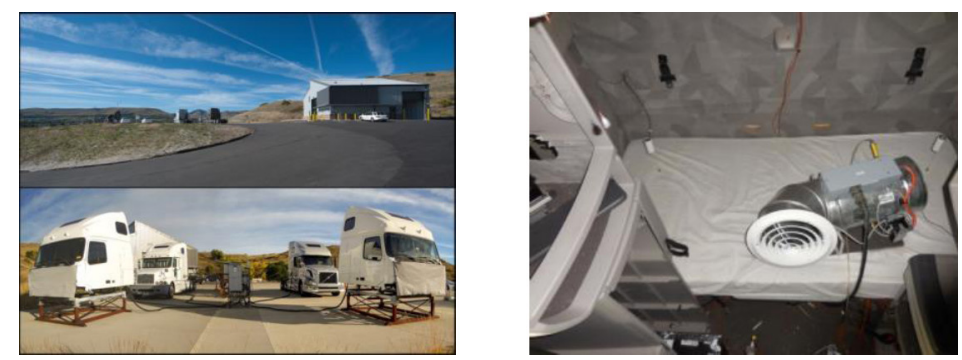

Figure 2. A (left), NREL's Vehicle Testing and Integration Facility; B (right), UA test heater in sleeper
During initial shakedown tests the diffuser vent on the heater was oriented horizontally, directing exhaust hot air upwards and to the sides. This setup resulted in strong air stratification in the sleeper (Figure 3A). After re-orienting the diffuser in a vertical plane (as shown in Figure 2B) air stratification in the sleeper was essentially eliminated (Figure 3B). This heater design and diffuser vent exit orientation provided sleeper air temperature uniformity within $\pm 2{ }^{\circ} \mathrm{C}$.
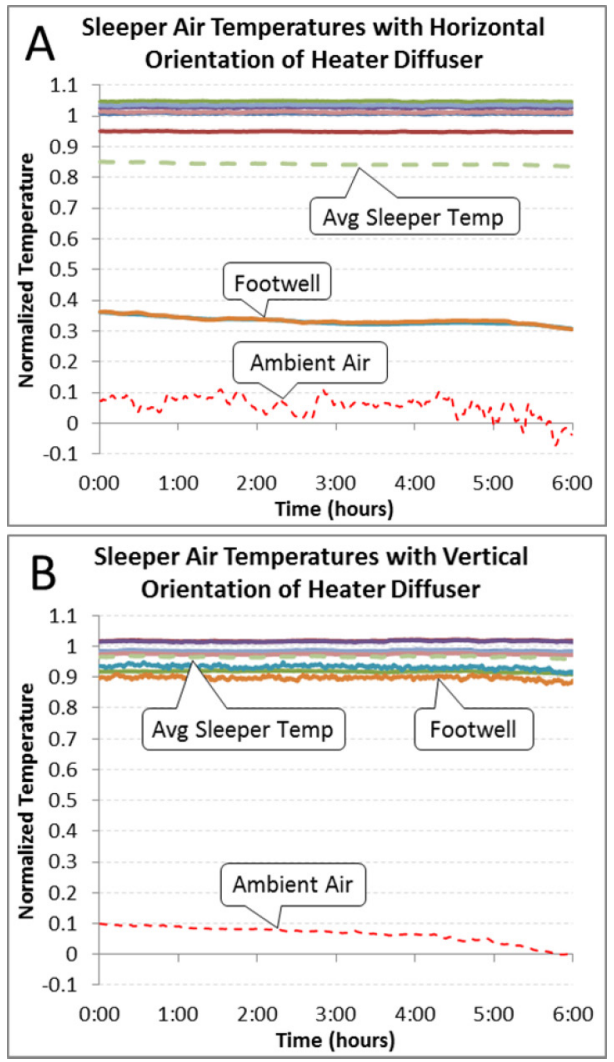

Figure 3. Test cab sleeper air temperatures normalized by temperature setpoint with horizontal (A) and vertical (B) orientation of heater diffuser vent

The UA value of the sleeper was calculated by measuring the heater power and the temperature difference between the interior air temperature and ambient temperature as described in Equation 1:

$$
U A=\frac{Q}{T_{\text {Sleeper }}-T_{\text {Ambient }}}
$$

where UA is the overall heat transfer coefficient [W/K], Q is the heater power $[\mathrm{W}], \mathrm{T}_{\text {Sleeper }}\left[{ }^{\circ} \mathrm{C}\right]$ is the average sleeper cab air temperature, and $\mathrm{T}_{\text {Ambient }}\left[{ }^{\circ} \mathrm{C}\right]$ is the local air temperature taken inside a naturally aspirated radiation shield at the weather station collocated at the test site.

If the total area of heat transfer in the sleeper is known, this test can be used to determine a truck's thermal resistance, or R-value, as described in Equation 2:

$$
R=\frac{A}{U A}
$$


where $\mathrm{R}\left[\mathrm{m}^{2} \cdot \mathrm{K} / \mathrm{W}\right]$ is the total sleeper cab resistance, and $\mathrm{A}$ is the total area of the sleeper boundaries $\left[\mathrm{m}^{2}\right]$. Due to the uncertainty in defining the total area of heat transfer in the sleeper, results are reported in terms of UA. It is worth noting that UA is inversely proportional to the overall resistance.

To account for normal day-to-day variations in weather conditions, the control buck was used as a reference. All vehicles will have some thermal performance variation due to differences in climate control systems, manufacturing, leakage, and other factors. To account for this, the control cab was calibrated to the test cab while both bucks were in a baseline configuration. The control cab can then be used as an accurate reference for the behavior of the test cab in a baseline configuration.

To further minimize the impact of weather variation on the test results, environmental screening criteria were established for a valid heating test day. Net downwelling infrared radiation (IR) was measured using Kipp \& Zonen CG4 pyrgeometer located at NREL's Solar Radiation Research Laboratory's weather station to characterize the cloud cover at night. Net downwelling IR is the difference between upward radiation from a surface to the sky and the downwelling, incoming radiation from the atmosphere. Cloud cover will increase the downwelling IR from the atmosphere to the surface and thus decrease the net loss of heat from the surface. A net downwelling IR of more than $85 \mathrm{~W} / \mathrm{m}^{2}$ lost from the surface was determined to indicate a clear night sky condition. Hourly average wind speeds were filtered to below $3.58 \mathrm{~m} / \mathrm{s}$ to limit the impact of wind variability. Wind speed below this limit was found to have little influence on UA.

To minimize the impact of transient effects, one-hour segments were selected that met stability criteria for ambient temperature and heater power. The maximum allowable ambient temperature change in the hour interval was $3^{\circ} \mathrm{C}$, and the maximum allowable heater power change was $15 \%$. The one-hour segments also had to be after midnight and before daybreak to avoid any influence of sunset or sunrise.

The average interior sleeper air temperature was calculated by averaging eight thermocouples, with six located in accordance with the American Trucking Association Technology Maintenance Council's recommended practice RP422A [ $\underline{8}$ ], as shown in Figure 4B. Similarly, the average cab air temperature was calculated by averaging six thermocouples with four located in accordance with RP422A, illustrated in Figure 4A. The addition of two thermocouples located in both the cab and sleeper air spaces improved the average air temperature measurement by more accurately capturing the air temperature distribution.

A National Instruments SCXI data acquisition system was used to record measurements at a sampling frequency of $1.0 \mathrm{~Hz}$, which was averaged over 1-minute intervals. Each cab had over 40 calibrated type $\mathrm{K}$ thermocouples for a variety of surface and air temperature measurements. An isothermal bath and a reference probe were used for thermocouple calibration, achieving a U95 uncertainty of $\pm 0.32^{\circ} \mathrm{C}$ in accordance with American Society of Mechanical Engineers standards [9]. Air temperature sensors were equipped with a double concentric cylindrical radiation shield to prevent errors due to direct solar radiation. The heater electrical power consumption was measured using Yokogawa watt meters with the accuracy of $\pm 0.2 \%$ reading. Weather data were collected from both NREL's Solar Radiation Research Laboratory and NREL's Vehicle Testing and Integration Facility [10] weather stations, which together feature more than 160 instruments dedicated to high-quality measurements of solar radiation and other meteorological parameters.
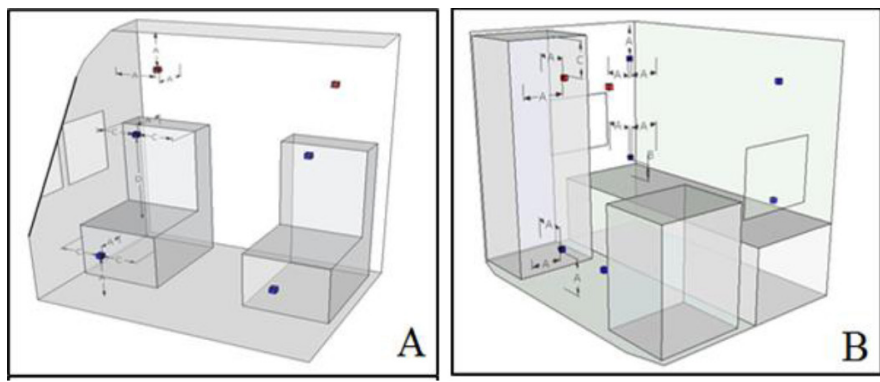

Figure 4. (A) $\mathrm{Cab}$ and (B) Sleeper thermocouple locations. Dimensions: $\mathrm{A}=$ $12 ", \mathrm{~B}=6 ", \mathrm{C}=18$ ". Blue: TMC standard []] ; red: NREL added.

\section{RESULTS}

\section{Baseline Testing}

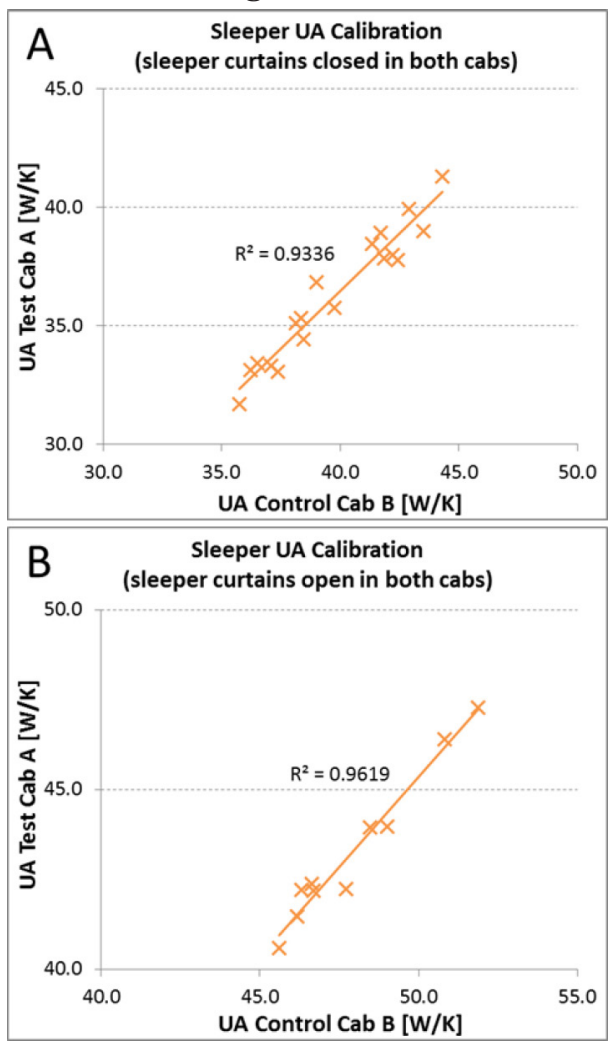

Figure 5. UA calibration results: A. Sleeper with standard sleeper curtain and shades, B. Sleeper with window shades only and no sleeper curtain

For the Complete-Cab Thermal Load Reduction Package experimental evaluation, the heater system was calibrated for the test and control bucks using the baseline configuration in both bucks. Two configurations were calibrated: a standard original equipment manufacturer insulation package with standard sleeper curtain and privacy shades, and a privacy-shade-only case with no sleeper 
curtain. The bucks were painted different colors, but because the testing was conducted at night and the paint emissivity was very similar, any effects due to this were negligible. The calibration data for the Complete-Cab Thermal Load Reduction Package UA baseline is shown in Figure 5. The figures contain only data that meet the weather and stability screening criteria described in the approach section. Both data sets show a strong linear correlation with a coefficient of determination $\left(\mathrm{R}^{2}\right)$ of 0.934 and 0.962 for the standard and no-curtain configurations, respectively.

\section{Thermal Load Reduction Package Testing}

The test buck thermal load reduction package was tested for multiple configurations as summarized in Tables $1, \underline{2}$ and $\underline{3}$. As previously discussed, one-hour segments that met the stability criteria were selected for multiple test days. These stable segment averages were then averaged to calculate the UA reduction and corresponding standard deviations $(\sigma)$ for each configuration. Applying only the advanced curtains and shades to the standard insulation resulted in a $20.6 \%$ reduction in UA. The advanced insulation alone was also effective at reducing the heating load, yielding a $20.7 \%$ reduction in UA. Applying the full thermal load reduction package with both advanced curtains and shades resulted in a $43 \%$ reduction in UA.

Table 1. Thermal load reduction with advanced insulation

\begin{tabular}{|l|c|c|c|c|c|}
\hline \multicolumn{1}{|c|}{ Configuration } & Insulation & $\begin{array}{c}\text { Privacy shades } \\
\text { on windshield }\end{array}$ & $\begin{array}{c}\text { Sleeper } \\
\text { curtains }\end{array}$ & $\begin{array}{c}\text { Reduction } \\
\text { in UA }\end{array}$ & $\begin{array}{c}\text { Standard } \\
\text { Deviation } \\
(\boldsymbol{\sigma})\end{array}$ \\
\hline Baseline with sleeper curtains closed & Standard & Standard & Standard & - & - \\
Advanced curtains & Standard & Advanced & Advanced & $20.6 \%$ & $0.9 \%$ \\
Advanced insulation & Advanced & Standard & Standard & $20.7 \%$ & $0.4 \%$ \\
Complete cab solution & Advanced & Advanced & Advanced & $\mathbf{4 3 . 0 \%}$ & $\mathbf{1 . 6 \%}$ \\
\hline
\end{tabular}

To build on these results, the insulation was improved further by adding an additional insulation layer with a reflective barrier to the walls and ceiling as previously described. This is the "advanced plus thermal load reduction" configuration. This layer fit between the structural members and the inner panels. The "advanced plus configuration" results are shown in Table 2. This insulation improvement resulted in an increase in the UA reduction for the insulation-only case with a $33.6 \%$ reduction in UA. Adding this insulation improved the full thermal load reduction package, reducing UA by $53.3 \%$. The third case in Table 2 compares the advanced insulation and privacy shades without a sleeper curtain to the baseline with a standard curtain. In some cases, drivers may want a more spacious feeling and not use a sleeper curtain during rest periods. This would provide more space to the occupant, but does reduce the overall improvement substantially. By opening the curtain, a larger volume of air will be conditioned and walls without improved insulation will be exposed to higher interior temperatures as compared to the baseline case with the standard curtains closed, resulting in higher thermal losses to the colder surroundings.

Table 2. Thermal load reduction with advanced plus insulation

\begin{tabular}{|l|c|c|c|c|c|}
\hline \multicolumn{1}{|c|}{ Configuration } & Insulation & $\begin{array}{c}\text { Privacy shades } \\
\text { on windshield }\end{array}$ & $\begin{array}{c}\text { Sleeper } \\
\text { curtains }\end{array}$ & $\begin{array}{c}\text { Reduction } \\
\text { in UA }\end{array}$ & $\begin{array}{c}\text { Standard } \\
\text { Deviation } \\
(\mathbf{\sigma})\end{array}$ \\
\hline Baseline with sleeper curtains closed & Standard & Standard & Standard & - & - \\
Advancedt insulation & Advanced+ & Standard & Standard & $33.6 \%$ & $0.7 \%$ \\
Complete cab solution+ & Advanced+ & Advanced & Advanced & $\mathbf{5 3 . 3 \%}$ & $\mathbf{0 . 7 \%}$ \\
Adv+ insulation \& adv shades & Advanced+ & Advanced & - Open - & $\mathbf{2 1 . 6 \%}$ & $0.5 \%$ \\
\hline
\end{tabular}

The second calibration process was used to investigate the impact of the insulation and privacy shades on a vehicle not using a sleeper curtain, as shown in Figure 5B. The impact of the insulation technologies was then compared against the baseline with no sleeper curtain as shown in Table 3 . These results also show strong improvements over the no-sleeper curtain baseline.

Table 3. Thermal load reduction with baseline sleeper curtains open

\begin{tabular}{|l|c|c|c|c|c|}
\hline \multicolumn{1}{|c|}{ Configuration } & Insulation & $\begin{array}{c}\text { Privacy shades } \\
\text { on windshield }\end{array}$ & $\begin{array}{c}\text { Sleeper } \\
\text { curtains }\end{array}$ & $\begin{array}{c}\text { Reduction } \\
\text { in UA }\end{array}$ & $\begin{array}{c}\text { Standard } \\
\text { Deviation } \\
(\boldsymbol{\sigma})\end{array}$ \\
\hline Baseline with sleeper curtains open & Standard & Standard & - Open - & - & - \\
Adv insulation \& adv shades & Advanced & Advanced & - Open - & $27.4 \%^{*}$ & $0.7 \%$ \\
Adv+ insulation \& adv shades & Advanced+ + & Advanced & - Open - & $33.9 \%^{*}$ & $0.4 \%$ \\
\hline
\end{tabular}

\section{SUMMARY/CONCLUSIONS}

NREL's CoolCab project aims to reduce HVAC loads and resulting idling fuel consumption while maintaining driver comfort when long-haul trucks are parked during a rest period. To achieve this, NREL researchers have collaborated with partners Volvo Group North America, Aearo Technologies, and PPG Industries to develop and test a thermal load reduction package that uses ultra-white paint, advanced insulation, and advanced curtains and window shades. Overall heat transfer coefficient (UA) testing of this package demonstrated a $43 \%$ reduction in heating loads, complementing the $35.7 \%$ reduction in cooling loads shown previously and exceeding the $30 \%$ reduction goal. Adding an additional layer of advanced insulation with a reflective barrier improved this to a $53.3 \%$ reduction in heating loads. Future work will use NREL's rapid HVAC load analysis tool, CoolCalc, to model the baseline insulation and advanced insulation packages. Simulations over a typical meteorological year will be performed for 200 weather stations identified as most representative of long-haul truck vehicle miles traveled. This will be combined with air conditioning and vehicle models to quantify fuel use and payback period impacts of these thermal load reduction technologies.

\section{REFERENCES}

1. Gaines, L., Vyas, A., and Anderson, J., "Estimation of Fuel Use by Idling Commercial Trucks." Presented at 85th Annual Meeting of the Transportation Research Board, Washington, D.C., Jan. 22-26, 2006; Paper No. 06-2567.

2. Torrey, F., and Murray, D., "An Analysis of the Operational Costs of Trucking: A 2014 Update." American Transportation Research Institute. Atlanta, GA. 2014.

3. "Idling Regulations Compendium." American Transportation Research Institute, accessed September 16, 2013: http://atri-online. org/2013/02/20/idling-regulations-compendium/.

4. "Greenhouse Gas Emissions Standards and Fuel Efficiency Standards for Medium- and Heavy-Duty Engines and Vehicles, Final Rule." Federal Register 76 (15 September, 2011): 57106-57513.

5. Roeth, M., Kircher, D., Smith, J., and Swim, R. Barriers to the Increased Adoption of Fuel Efficiency Technologies in the North American OnRoad Freight Sector. Report for the International Council for Clean Transportation. NACFE. July 2013.

6. Lustbader, J., Kreutzer, C., Jeffers, M., Adelman, S. et al., "Impact of Paint Color on Rest Period Climate Control Loads in Long-Haul Trucks," SAE Technical Paper 2014-01-0680, 2014, doi:10.4271/201401-0680.

7. Lustbader, J., Kreutzer, C., Adelman, S., Yeakel, S. et al., "Sleeper Cab Climate Control Load Reduction for Long-Haul Truck Rest Period Idling," SAE Technical Paper 2015-01-0351, 2015, doi:10.4271/2015$\underline{01-0351 .}$ 
8. “Cab Insulation Testing Methodology.” RP422A-1-9. Technology and Maintenance Council's Recommended Maintenance Practices Manual, 2010-2011 Edition. Arlington, VA: American Trucking Association, p. RP422A 1.

9. Dieck, R.H., Steele, W.G., and Osolsobe, G., Test Uncertainty. ASME PTC 19.1-2005. New York, NY: American Society of Mechanical Engineers. 2005.

10. "Vehicle Testing and Integration Facility." National Renewable Energy Laboratory, http://www.nrel.gov/midc/vtif rsr/

\section{CONTACT INFORMATION}

Jason A. Lustbader

Heavy Vehicle Thermal Management Team Lead

National Renewable Energy Laboratory

Jason.Lustbader@nrel.gov

303-275-4443

\section{ACKNOWLEDGMENTS}

1. Special thanks to our additional industry partner PPG Industries.

2. Additional thanks to John Rugh and Lisa Fedorka (NREL).

This work was supported by the U.S. Department of Energy under Contract No. DE-AC36-08GO28308 with the National Renewable Energy Laboratory. Funding was provided by U.S. DOE Office of Energy Efficiency and Renewable Energy Vehicle Technologies Office.

The U.S. Government retains and the publisher, by accepting the article for publication, acknowledges that the U.S. Government retains a nonexclusive, paid-up, irrevocable, worldwide license to publish or reproduce the published form of this work, or allow others to do so, for U.S. Government purposes.

\section{DEFINITIONS/ABBREVIATIONS}

A - area

$\mathbf{A} / \mathbf{C}$ - air conditioning

HVAC - heating, ventilating, and air conditioning

IR - infrared radiation

NREL - National Renewable Energy Laboratory

$\mathbf{Q}$ - heat power

$\mathbf{R}$ - thermal resistance

$\mathbf{R}^{2}$ - coefficient of determination

$\mathbf{T}$ - temperature

UA - overall heat transfer coefficient

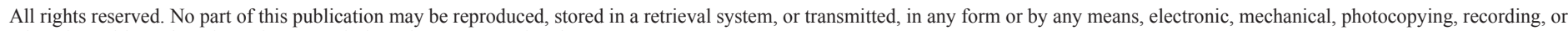
otherwise, without the prior written permission of SAE International. 